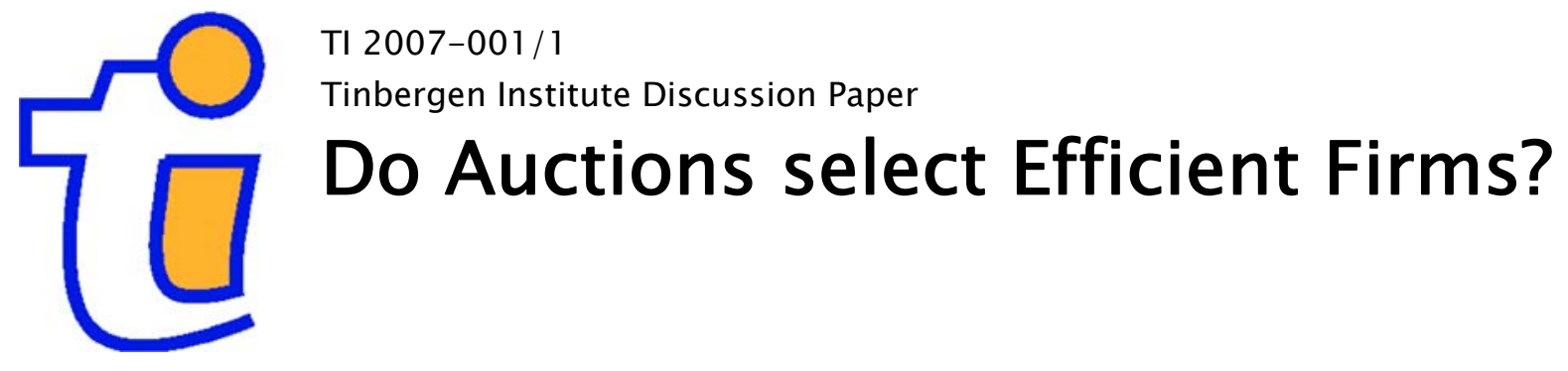

Maarten C.W. Janssen ${ }^{1,2}$

Vladimir A. Karamychev ${ }^{7}$

${ }^{\prime}$ Erasmus Universiteit Rotterdam, 2 Tinbergen Institute. 


\section{Tinbergen Institute}

The Tinbergen Institute is the institute for economic research of the Erasmus Universiteit Rotterdam, Universiteit van Amsterdam, and Vrije Universiteit Amsterdam.

Tinbergen Institute Amsterdam

Roetersstraat 31

1018 WB Amsterdam

The Netherlands

Tel.: $\quad+31(0) 205513500$

Fax: $\quad+31(0) 205513555$

Tinbergen Institute Rotterdam

Burg. Oudlaan 50

3062 PA Rotterdam

The Netherlands

Tel.: $\quad+31(0) 104088900$

Fax: $\quad+31(0) 104089031$

Most TI discussion papers can be downloaded at http:/ /www.tinbergen.nl. 


\title{
Do Auctions Select Efficient Firms? ${ }^{1}$
}

\author{
Maarten C. W. Janssen \\ Vladimir A. Karamychev
}

Tinbergen Institute and Erasmus University Rotterdam

\begin{abstract}
This paper considers a government auctioning off multiple licenses to firms who compete in a market after the auction. Firms have different costs, and cost efficiency is private information at the auction stage and the market competition stage. If only one license is auctioned, standard results say that the most efficient firm wins the auction (license) as it will get the highest profit in the aftermarket, i.e., it has the highest valuation for the license. This paper argues that this result does not generalize to the case of multiple licenses and aftermarket competition. In particular, we determine conditions under which auctions may select inefficient firms and therefore lead to an inefficient allocation of resources. Strategic interactions in the aftermarket, in particular firms' preferences to compete with the least cost-efficient firms rather than with the most efficient firms, are responsible for our result.
\end{abstract}

Key Words: Auctions, cost-efficiency, aftermarkets

JEL Classification: D43, L11, L13.

\footnotetext{
${ }^{1}$ We thank Larry Ausubel, Benny Moldovanu and audiences at European University Institute, Erasmus University Rotterdam and Tinbergen Institute for helpful comments and suggestions.
} 


\section{Introduction}

In many liberalization or privatization projects, governments eventually face the issue how to select firms that will provide the formerly publicly provided service. One of the advantages of using auctions as a selection mechanism, so it is often thought, is that auctions select the most cost-efficient firms. Markets where more cost-efficient firms are active typically yield more efficient market outcomes than when these same markets are served by less cost-efficient firms, i.e., other things being equal cost-efficiency is good for overall economic welfare. One forceful statement of this view is by Demsetz (1968). Demsetz argues that competition for the market may be a good substitute for competition in the market. Moreover, in a monopoly context he argues that the most cost-efficient firm will win the competition for the market (read: will win the auction). In this paper, we will refer to this result as the monopoly result of Demsetz. This result has permeated a large literature on procurement issues and, indeed, Laffont and Tirole (2002, pp. 307-8) state that if one ignores the processing, capture and dynamic costs of auctions, it is easy to see that auctions typically select the firm with the lowest cost.

Recently, many governments have relied on a combination of competition for and competition in the market. An important case in point is the wave of $3 \mathrm{G}$ mobile telephony spectrum auctions that have been held around the world (see, e.g., Klemperer 2002a, 2002b, Binmore and Klemperer 2002, and Jehiel and Moldovanu 2004 for overviews). In all of the $3 \mathrm{G}$ auctions, multiple licenses were sold and as there were more firms participating in the auction than available licenses, firms had to compete to obtain a license. Many governments formally or informally stated that efficient assignment of frequency spectrum was one of the goals to be achieved. With cost asymmetries between firms, efficient assignment implies that the most cost-efficient firms should win licenses, and indeed the Dutch government, among others, mentioned selecting the most efficient firms as one of the reasons for holding an auction (see, e.g., Janssen et al. 2001).

In this paper, we will argue however that the monopoly result of Demsetz does not carry over to the case of multiple licenses, i.e., to the case where firms compete in an oligopolistic fashion in the aftermarket. In particular, there are market conditions under which the most cost-efficient firms will not necessarily obtain the licenses, or even 
worse, that the least cost-efficient firms will necessarily secure them. The main reason that the Demsetz result does not generalize is that in an auction with multiple licenses, a strategic effect works against the Demsetz result. Basically, the strategic effect is present in almost all market settings as it simply confirms the fact that any firm prefers to compete with high-cost firms rather than with low-cost firms. Depending on the market conditions and the ex-ante distribution of firms' costs, the strategic effect can be so strong that the most cost-efficient firms make less profit in the aftermarket when they compete with each other than the least cost-efficient firms do.

More technically, we consider a standard multi-unit uniform-price auction where firms have private information about their costs, and overall economic efficiency requires the most efficient firms to win the auction. A strategy for the firms is a function specifying how a firm's bid depends on its efficiency parameter. The generalization of the Demsetz monopoly result to the case where multiple licenses are auctioned requires that the more efficient a firm is, the higher it bids in the auction, i.e., there should exist a monotone symmetric bidding equilibrium where firms' bidding strategy is increasing in their efficiency parameter. We identify conditions under which such a symmetric increasing bidding equilibrium exists and when it does not exit.

A first, more easily identifiable condition under which a symmetric increasing bidding equilibrium fails to exist is that firms' efficiency parameters are positively correlated (affiliated) so that learning one's own efficiency parameter provides information about other firms' private information. In practice, positive affiliation of firms' efficiency parameters may naturally arise in sectors where firms use similar production technologies and prices of inputs fluctuate with (macroeconomic) shocks that are common to all firms. Alternatively, firms may implement cost-saving technologies that arise from an exogenous stochastic process. In both cases, if a firm is more cost-efficient itself, it infers that all other firms are more cost-efficient as well. Therefore, more efficient firms expect to be competing with other efficient firms (who are known to be fierce competitors) and thus expect to make less profit in the aftermarket than less efficient firms. ${ }^{2}$ We will show, that for any oligopolistic market, no matter how weak the strategic effect is, there are distributions of firms' types for which a symmetric increasing bidding equilibrium does not exist.

\footnotetext{
${ }^{2}$ In other words, in an increasing bidding equilibrium there is a kind of winner's curse or adverse selection effect present, the strength of which depends on the type of bidder. Bidders optimally "adjust" their bids for this effect and as the effect is stronger for more efficient firms, highly efficient firms may "adjust" their bid so much that the increasing bidding equilibrium strategy is destroyed.
} 
A second, more surprising condition under which a symmetric increasing bidding equilibrium fails to exist is where firms' efficiency parameters are ex-ante independent. Despite firms' types being ex-ante independent, the types of firms that win licenses will be correlated. This is so because all winning firms outbid the firm with the highest loosing bid. As this ex post form of positive correlation (affiliation) actually is the only correlation that is relevant for determining the optimal bidding strategy, the intuitive reason for the nonexistence of a symmetric increasing bidding equilibrium is then the same as above. We will show that in this case of statistically independent types an increasing equilibrium fails to exist only if the strategic effect is sufficiently strong.

When one of these two conditions holds, a symmetric increasing bidding equilibrium does not exist. This implies that only $(i)$ asymmetric equilibria exist in which different firms have different bidding functions, or ( $i i)$ the equilibrium bidding functions are not monotone, or (iii) firms use random bidding strategies, or (iv) a decreasing equilibrium exists. In all of these four cases, there is at least a positive probability that less efficient firms will bid more than more efficient firms and therefore obtain the licenses. Thus, if firms' types are highly correlated, or the strategic effect is strong enough, the overall outcome is inefficient with positive probability. ${ }^{3}$

We also show, by means of an example, that if firms' types are correlated and the strategic effect is strong enough, a unique monotone symmetric bidding equilibrium is decreasing. In this case, auctions always select the least efficient firms implying lower overall welfare than any other selection mechanism.

The rest of the paper is organized as follows. Section 2 describes the two-stage model with an auction stage and a market competition stage. In Section 3 we then provide necessary and sufficient conditions for an increasing equilibrium to exist and illustrate what these general conditions imply in case of Bertrand and Cournot competition in the aftermarket. Then, in section 4 , we provide an example in which a unique monotone symmetric bidding equilibrium exists and that it is decreasing. Section 5 concludes and provides a discussion of related literature and remaining issues. The appendix contains all proofs.

\footnotetext{
3 There are now many papers studying inefficiencies created by auctions due to aftermarket competition. For a recent overview, see Jehiel and Moldovanu (2006). Hoppe, Jehiel and Moldovanu (2006) focus on the interaction between incumbents and entrants, Janssen (2006) considers how auctions may lead to coordination in the market stage and Janssen and Karamychev (2006) study selection effects in markets where demand uncertainty is important. Jehiel and Moldovanu (1996) and Jehiel, Moldovanu and Stacchetti (1996) show that even when one license is auctioned, inefficiencies may arise due to the existence of externalities between the bidders.
} 


\section{The Model}

Access to the aftermarket is limited to the firms that have obtained licenses to operate in the market. The government allocates $n \geq 2$ licenses in a multi-unit auction to the highest bidding firms, and we assume that $N \geq(n+1)$ firms participate in the auction. In the oligopolistic aftermarket, firms compete by simultaneously choosing a value of the strategic variable $s$. Depending on the market, we can interpret $s$ as either a price $p$ or a quantity $q$, or any other relevant strategic variable. The profit $\pi^{i}$ of firm $i$ is determined by the level of $s$ that firm $i$ and the other $(n-1)$ firms choose, and by the firm's efficiency parameter $e_{i}$. As we assume that $\pi^{i}$ is symmetric in all $s_{j}$ for $j \neq i$, it can be written as

$$
\pi^{i}=\pi\left(s_{i}, s_{-i}, e_{i}\right),
$$

where $S_{-i}$ is a vector of strategic variables chosen by all other firms. To shorten notation, we denote the partial derivatives of $\pi$ as follows:

$$
\pi_{i} \equiv \partial \pi / \partial s_{i}, \pi_{j} \equiv \partial \pi / \partial s_{j} \text { for } j \neq i, \pi_{e} \equiv \partial \pi / \partial e_{i}, \pi_{i, i} \equiv \partial^{2} \pi / \partial s_{i} \partial s_{j}, \text { etc. }
$$

The efficiency parameter $e_{i}$ positively influences the profit of firm $i$ by reducing its total as well as marginal costs. Therefore, for a typical cost function $f(e, q)$ of a firm we will have:

$$
f_{e}(e, q)<0, f_{q}(e, q)>0 \text {, and } f_{e, q}(e, q)<0 .
$$

When firms compete in quantities (Cournot competition), $s_{i}=q_{i}$ and firms' profit function is given by

$$
\pi\left(q_{i}, q_{-i}, e_{i}\right)=q_{i} p\left(\sum_{j} q_{j}\right)-f\left(e_{i}, q_{i}\right),
$$

so that $\pi_{e}=-f_{e}>0$ and $\pi_{i, e}=-f_{e, q}>0$. When firms compete in prices (differentiated Bertrand competition), $s_{i}=p_{i}$ and firms' profit function is given by

$$
\pi\left(p_{i}, p_{-i}, e_{i}\right)=q\left(p_{i}, p_{-i}\right) p_{i}-f\left(e_{i}, q\left(p_{i}, p_{-i}\right)\right),
$$

where $q\left(p_{i}, p_{-i}\right)$ is firm $i$ s market demand, so that $\pi_{e}=-f_{e}>0$ and $\pi_{i, e}=-f_{e, q} q_{i}<0$.

In order to ensure the existence, uniqueness and stability of the Nash equilibrium in the aftermarket, firms' marginal profit function must satisfy a stability requirement. We follow Bulow et al. (1985) and assume in the case of strategic complements, where $\pi_{i, j}>0$, that $\left(\pi_{i, i}+\sum_{k \neq i} \pi_{i, k}\right)<0$ and in case of strategic substitutes, where $\pi_{i, j}<0$, that $\left(\pi_{i, i}-\pi_{i, j}\right)<0$. 
We analyze the case where the government organizes a multi-unit uniform-price auction to allocate the $n$ licenses, where all the winning firms pay the same license fee $w$, which is equal to the highest non-winning bid. This uniform-price auction allows us to simplify the exposition of results while keeping the formulation of the aftermarket competition stage quite general. In the main body of the paper we assume that resale of licenses is not allowed. In the final section, we discuss how allowing for different auction formats and resale of licenses after the auction will affect our results.

A firm's efficiency parameter $e_{i}, i . e .$, the type of firm $i$, is its private information in the auction stage. The prior joint distribution of types is denoted by $F\left(e_{i}, e_{-i}\right)$. This distribution has a finite support $[\underline{e}, \bar{e}]$, and is assumed to be weakly affiliated (thus allowing for statistical independence). A firm $i$ submits a bid $b_{i}$ based on $e_{i}$. We denote a monotone symmetric equilibrium bidding function by $b(e)$, so that firm $i$ bids $b\left(e_{i}\right)$ in equilibrium.

Depending on what information is revealed immediately after the auction is held, three different scenarios can be considered:

a) A private information scenario, where neither firms' types nor the winning bids become public.

b) An imperfect information scenario, where only the bids of the winning firms but not their types become public.

c) A full information scenario, where types of all winning firms become public.

In what follows, we mainly focus on the private information scenario. The imperfect information scenario is too complicated to analyze as signaling issues significantly complicate firms' bidding behavior. As each firm has an incentive to pretend to be more efficient than it actually is, the auction stage would have to be analyzed as an $N$ firm signaling game with each player being a sender and a potential receiver of signals. ${ }^{4}$ The full information scenario, on the other hand, does not seem to be realistic. Moreover, this scenario can be analyzed in a similar way to the private information scenario, as we will briefly indicate in footnote 5 below.

In the private information scenario, a type $e_{i}$ paying a license fee $w$ and choosing $s_{i}$ in the aftermarket has an expected market profit conditional on winning the auction of

\footnotetext{
${ }^{4}$ Goeree (2003) contains an analysis of how single-agent signaling affects bidding behavior in auctions.
} 


$$
E\left(\pi\left(s_{i}, s_{-i}, e_{i}\right) \mid e_{i}, b\left(e_{l}\right) \leq w<b\left(e_{k}\right)\right),
$$

where we indicate all winning firms other than firm $i$ by the index $k$ and all loosing firms by index $l$. Maximizing expected profit with respect to $s_{i}$ and assuming that all other winning firms choose $s_{k}$ optimally yields the first-order conditions defining firms' aftermarket Nash equilibrium strategy. In case the bidding function $b(e)$ monotonically increases, we denote it as $b^{(+)}(e)$, and write these first-order conditions as follows:

$$
\left.0=E\left(\pi_{i}\left(s_{i}^{*}, s_{-i}^{*}, e_{i}\right)\right) e_{i}, e_{l} \leq z<e_{k}\right), i=1, \ldots, n,
$$

where $z$ denotes the type of firm that submits the $n^{\text {th }}$ highest bid among $(N-1)$ firms other than firm $i$ determining the license fee $w$, i.e., $w=b^{(+)}(z)$. Under the assumptions that we made about the profit function $\pi\left(s_{i}, s_{-i}, e_{i}\right)$, these first-order conditions uniquely define a market stage Nash equilibrium strategy $s_{i}^{*}=s\left(e_{i}, z\right)$.

\section{When an increasing bidding equilibrium does not exist}

We are now ready to analyze the necessary and sufficient conditions for an increasing symmetric bidding equilibrium to exist. We first derive these conditions for the general case described in the previous section. Then we analyze two sets of circumstances (firms' types being independently distributed, and affiliated types) under which the necessary conditions cannot be satisfied so that the auction stage does not have an increasing symmetric bidding equilibrium. With independent types, we also indicate what these conditions imply in case of Bertrand and Cournot competition.

Let $b^{(+)}(e)$ be an increasing symmetric equilibrium bidding function and $s_{i}^{*}=s\left(e_{i}, z\right)$ be the corresponding firms' aftermarket Nash equilibrium strategy. Denoting a firm's reduced-form profit by $\bar{\pi}\left(e_{i}, e_{-i}, z\right)$, i.e.,

$$
\bar{\pi}\left(e_{i}, e_{-i}, z\right) \equiv \pi\left(s_{i}^{*}, s_{-i}^{*}, e_{i}\right),
$$

allows us to write the expected profit of type $x$ conditional on getting a license as

$$
v^{(+)}(x, z) \equiv E\left(\bar{\pi}\left(e_{i}, e_{-i}, z\right) \mid e_{i}=x, e_{l} \leq z<e_{k}\right) .
$$

The function $v^{(+)}(x, z)$ is a firm's valuation function, which is used in the auction stage to determine the optimal bidding strategy. The following proposition derives an equilibrium bidding function and necessary and sufficient conditions for an increasing symmetric bidding equilibrium to exist. 
Proposition 1. If $v_{x}^{(+)}>0$ and $v_{x}^{(+)}(e, e)+v_{z}^{(+)}(e, e)>0$ for all $e \in[\underline{e}, \bar{e}]$, then there exists a unique symmetric increasing bidding equilibrium given by $b^{(+)}(e)=v^{(+)}(e, e)$. If the equilibrium exists, then $v_{x}^{(+)}(e, e) \geq 0$ and $v_{x}^{(+)}(e, e)+v_{z}^{(+)}(e, e) \geq 0$ for all $e \in[e, \bar{e}]$.

The statements made in Proposition 1 can be understood as follows. Suppose that $x=z$. In other words, suppose that firm $i$ and another firm, let us say firm $m$, have the same type, i.e., $e_{i}=x=z=e_{m}$, so that they together determine the auction price $w$, and $e_{k}>z$ for all other winning firms $k$. In this case, firms $i$ and $m$ compete for only one remaining license. They will bid their entire expected market profits $v^{(+)}(z, z)$, so that the equilibrium bidding function $b^{(+)}(e)$ must satisfy $b^{(+)}(z)=v^{(+)}(z, z)$.

Suppose now that $x$ is marginally larger than $z$. Then, in order to get a license, firm $i$ must get a marginally higher expected profit $v^{(+)}(x, z)$ than firm $m$, so that firm $i$ can bid marginally higher than firm $m$. Thus, $v^{(+)}(x, z)$ must be an increasing function of $x$ at $x=z$, i.e., $v_{x}^{(+)}(e, e) \geq 0$ is the first necessary condition. The other necessary condition $v_{x}^{(+)}(e, e)+v_{z}^{(+)}(e, e) \geq 0$ then guarantees that the actual bid $v^{(+)}(x, x)$ of firm $i$ is indeed higher than the bid $v^{(+)}(z, z)$ of firm $m$.

On the other hand, if $b^{(+)}(e)=v^{(+)}(e, e)$ is a strictly increasing bidding function, the sufficient condition $v_{x}^{(+)}>0$, which basically is the second-order condition for profit maximization, guarantees that a firm has no profitable deviation from $b^{(+)}(e)$.

From the point of view of a winning firm $i$, the types of all other $(n-1)$ winning firms are affiliated even if the types are ex-ante independent. The degree of this affiliation, in general, is determined by firm $i$ 's own type and by the ex-ante distribution of types. In the limit case, when types of all competitors of firm $i$ are perfectly correlated, i.e., when $e_{k}=z$ for all $k$, the partial derivatives of the reduced-form profit function $\bar{\pi}$ can be analytically calculated. This is the content of the following lemma.

Lemma 1. In case $e_{k}=z$ for all $k$, the partial derivatives of the reduced-form profit function of firm $i \bar{\pi}\left(e_{i}, e_{-i}, z\right)$ at $e_{i}=e_{j}=z=x$ are:

$$
\begin{aligned}
& \overline{\pi_{i}}(x, x, x)=\pi_{e}>0, \\
& \overline{\pi_{j}}(x, x, x)=-\frac{\pi_{j} \pi_{i, e}}{\pi_{i, i}}<0 \text { and }
\end{aligned}
$$




$$
\overline{\pi_{z}}(x, x, x)=\frac{(n-1)^{2} \pi_{j} \pi_{i, j} \pi_{i, e}}{\left(\pi_{i, i}+(n-1) \pi_{i, j}\right) \pi_{i, i}} .
$$

Lemma 1 turns out to be useful in the rest of this section. Using a continuity argument, it is easy to see that the inequalities $\bar{\pi}_{i}>0$ and $\overline{\pi_{j}}<0$ also hold if competitors' types are highly (but not perfectly) correlated, and if $x$ and $z$ are close to each other (but not coincide). Hence, in accordance with Lemma 1, if the ex post correlation of all winning firms' types is large, the direct effect $\bar{\pi}_{i}$ is always positive, i.e., each firm wants to be more efficient, and the indirect strategic effect $\overline{\pi_{j}}$ is negative, i.e., each firm wants to compete with less efficient firms. It follows that there is a tension in the auction stage of the model. On one hand, the positive direct effect forces a firm to bid higher if the firm is more efficient. On the other hand, the negative strategic effect influences a firm' valuation through the ex post affiliation and forces a firm to bid lower if the firm is more efficient.

An interesting consequence of Lemma 1 is that the auction price $w=b^{(+)}(z)$ cannot be considered a sunk cost for a firm in the aftermarket stage, i.e., $\overline{\pi_{z}} \neq 0$. This is because the auction price effects the distribution of firms' competitors and through their aftermarket strategy it indirectly influences a firm's profits.

\section{Statistically independent type}

Using Proposition 1 and Lemma 1 as a general tool, we now first analyze the case where firms' types are independent. Let the firms' efficiency parameters $e_{i}$ be identically and independently distributed over a compact and bounded support in accordance with an arbitrary twice differentiable distribution function $F_{e}(x)$, which density is denoted by $f_{e}(x)$. The following proposition states a condition under which an increasing equilibrium fails to exist.

Proposition 2. If the condition

$$
2 \pi_{e}<\frac{(n-1) \pi_{j} \pi_{i, e}}{\left(\pi_{i, i}+(n-1) \pi_{i, j}\right)}
$$

holds at $e_{i}=e_{j}=\bar{e}$, then the auction stage does not have a symmetric increasing bidding equilibrium. 
We have argued above that firms' types (conditional on winning) are ex-post affiliated even if the types are ex-ante independent. Proposition 2 uses the fact that if $z$ is close to the upper end of the distribution $\bar{e}$, this affiliation is reasonably strong because the types of all winning firms will be between $z$ and $\bar{e}$. Together with a sufficiently strong strategic effect given by the inequality in Proposition 2, an increasing bidding equilibrium fails to exist. ${ }^{5}$

We will illustrate Proposition 2 by considering some specific functional forms under Cournot and differentiated Bertrand competition. These examples strengthen the idea conveyed in this section, namely that if the strategic effect is strong enough a symmetric increasing bidding equilibrium fails to exist. The examples identify conditions in terms of demand elasticities and cross-price effects guaranteeing a strong enough strategic effect.

\section{Example 1: Cournot competition.}

Let firms have constant marginal cost so that the cost function is $f(e, q)=q(c-e)$, with $c \geq \bar{e}$, and let market demand be characterized by a constant price elasticity $r$, i.e., $Q=p^{-r}$. Under Cournot competition, a firm's profit function becomes

$$
\pi\left(q_{i}, q_{-i}, e_{i}\right)=q_{i}\left(\left(\sum_{j} q_{j}\right)^{-1 / r}-\left(c-e_{i}\right)\right),
$$

so that equilibrium output levels at $e_{i}=e_{j}=e$ are given by

$$
q_{i}=q_{j}=q^{*}=\frac{1}{n}\left(\frac{(n r-1)}{n r(c-e)}\right)^{r} .
$$

Proposition 2 tells us that a sufficient condition for a symmetric increasing bidding equilibrium not to exist can be obtained by investigating the partial derivatives of the profit function at this point. One can easily calculate them to be:

$$
\begin{aligned}
& \pi_{j}=-\frac{(c-e)}{n r-1} \\
& \pi_{i, i}=-\frac{(2 n r-(1+r))(c-e)}{(n r-1) n r q^{*}}, \\
& \pi_{i, j}=-\frac{(n r-(1+r))(c-e)}{(n r-1) n r q^{*}},
\end{aligned}
$$

${ }^{5}$ One can see that the results of Proposition 1 and 2 also hold true in the full information scenario discussed above. The reason is that under the conditions of Lemma 1, all winning firms have the same type, and therefore Lemma 1 holds true in both (full and private) informational scenarios. Consequently, Proposition 2 holds in both settings. 


$$
\pi_{e}=q^{*} \text {, and } \pi_{i, e}=1 .
$$

Substituting these values into the condition of Proposition 2 we get that if $r<2 /(n+1)$ a symmetric increasing bidding equilibrium does not exist. Thus, if demand is relatively inelastic the strategic effect is strong enough to dominate the direct effect. This is quite intuitive as in this case a small reduction in total output (due to higher cost) has large price (and thus, profit) effects. On the other hand, we do not want this non-existence result to be driven be by the fact that the market stage equilibrium is not well-defined. It is easy to see that the stability condition $\left(\pi_{i, i}-\pi_{i, j}\right)<0$ that we imposed reduces in this case to $r>1 / n$, i.e., the price elasticity of demand should not be too small. Consequently, if

$$
r \in\left(\frac{1}{n}, \frac{2}{(n+1)}\right),
$$

the condition of Proposition 2 as well as the stability assumption mentioned in Section 2 are satisfied for any ex-ante independent distribution of types. Thus, for any number of licenses $n \geq 2$ that are auctioned there exist values of the price elasticity of demand such that an increasing bidding equilibrium does not exist. ${ }^{6}$

\section{Example 2: Differentiated Bertrand competition.}

If, to the contrary, firms compete in prices with the same cost function as in Example 1, and firms' market demands are linear and given by

$$
q\left(p_{i}, p_{-i}\right)=1-p_{i}+a \sum_{j \neq i} p_{j},
$$

then the profit function becomes

$$
\pi\left(p_{i}, p_{-i}, e_{i}\right)=\left(p_{i}-\left(c-e_{i}\right)\right)\left(1-p_{i}+a \sum_{j \neq i} p_{j}\right) .
$$

Equilibrium prices at $e_{i}=e_{j}=e$ can be easily calculated to be given by

$$
p_{i}=p_{j}=p^{*}=(1-(c-e)) /(2-a(n-1)) .
$$

Again, to invoke Proposition 2 we have to investigate the partial derivatives of the profit function $\pi$. One can easily see that at this point they are:

$$
\pi_{j}=a \frac{1-(c-e)(1-a(n-1))}{(2-a(n-1))},
$$

\footnotetext{
${ }^{6}$ In this example, quantities are strategic substitutes if $r \in(1 /(n-1), 2 /(n+1))$ as $\pi_{i, j}<0$, and are strategic complements if $r \in(1 / n, 1 /(n-1))$ as $\pi_{i, j}>0$.
} 


$$
\begin{aligned}
& \pi_{e}=\frac{1-(c-e)(1-a(n-1))}{(2-a(n-1))}, \\
& \pi_{i, i}=-2, \pi_{i, j}=a \text {, and } \pi_{i, e}=-1 .
\end{aligned}
$$

As in Example 1, we need take two constraints into account. On one hand, substituting these values into the condition of Proposition 2 we can check that if $a>4 /(3(n-1))$ a symmetric increasing bidding equilibrium does not exist. The parameter a measures the strategic effect in this case and this effect must be sufficiently strong. On the other hand, the stability condition $\left(\pi_{i, i}+\sum_{k \neq i} \pi_{i, k}\right)<0$ reduces in this case to $a<2 /(n-1)$, i.e., the strategic effect cannot be too large. Thus, if

$$
a \in\left(\frac{4}{3(n-1)}, \frac{2}{n-1}\right),
$$

a symmetric increasing bidding equilibrium does not exist for any ex-ante independent distribution of firms' types. Again, it is easy to see that for any $n \geq 2$ there are parameter values such that this is the case.

\section{Affiliated types}

In the examples above, we have shown that if the strategic effect is stronger than the direct effect then for any independent prior distribution of firms' types, an increasing equilibrium does not exist. It turns out that that even if the strategic effect is weak (but still exists) an increasing equilibrium may still fail to exist provided firms' types are exante affiliated. $^{7}$

In the sequel we consider a market stage with conditions that commonly hold in oligopoly markets, namely $\bar{\pi}_{i}>0$, i.e., firms prefer being more cost-efficient themselves, and $\overline{\pi_{j}}<0$, i.e., firms prefer competing with less cost-efficient competitors. For simplicity, we assume that firms' cost function is given by $f(e, q)=q(c-e), c \geq 2$, and that all efficiency parameters $e_{j}$ with probability a half are uniformly and independently distributed over the range $[0,1]$, and with probability a

\footnotetext{
${ }^{7}$ It is easy to see that if the strategic effect is completely absent, i.e., if $\overline{\pi_{j}}=\overline{\pi_{z}}=0$, so that firms have local monopolies, the Demsetz monopoly result continues to hold.
} 
half they are uniformly and independently distributed over the range $[1,2]$. If the type of firm $i$ is marginally below 1 , i.e., $e_{i}=1-\varepsilon$ where $\varepsilon>0$ is small, it expects to compete with firms which types are distributed over $[1-\varepsilon, 1]$, in which case:

$$
b^{(+)}(1-\varepsilon)=v^{(+)}(1-\varepsilon, 1-\varepsilon)=E\left(\bar{\pi}\left(1-\varepsilon, e_{-i}, 1-\varepsilon\right) \mid e_{k} \in[1-\varepsilon, 1]\right) .
$$

If, on the other hand, the type of firm $i$ is marginally above 1 , i.e., $e_{i}=1+\varepsilon$, the firm expects to compete with firms which types are distributed over $[1+\varepsilon, 2]$, in which case:

$$
b^{(+)}(1+\varepsilon)=v^{(+)}(1+\varepsilon, 1+\varepsilon)=E\left(\bar{\pi}\left(1+\varepsilon, e_{-i}, 1+\varepsilon\right) \mid e_{k} \in[1+\varepsilon, 2]\right) .
$$

It is easy to see that the bidding function is discontinuous and actually decreases at 1 :

$$
\lim _{\varepsilon \rightarrow 0}\left(b^{(+)}(1+\varepsilon)-b^{(+)}(1-\varepsilon)\right)=E\left(\bar{\pi}\left(1, e_{-i}, 1\right)-\bar{\pi}(1,1,1) \mid e_{k} \in[1,2]\right)<0,
$$

due to $\overline{\pi_{j}}<0$. Hence, a symmetric increasing bidding equilibrium fails to exist no matter how weak the strategic effect is.

\section{On decreasing bidding equilibria}

The analysis in the previous section leads us to a natural question, namely whether there exist market structures and types' distributions, for which not only an increasing equilibrium fails to exist, but instead a symmetric decreasing equilibrium does exist. In such an equilibrium, the least-efficient firms always submit the highest bids and obtain the licenses to compete in the aftermarket. In this section, we first argue that the strategic effect and ex-ante affiliation of firms' types are both necessary for a decreasing equilibrium to exist. Next, we provide an example of specific market conditions under which a decreasing equilibrium exists.

When a monotone symmetric equilibrium bidding function is a decreasing function, firm's valuation function $v^{(-)}(x, z)$ must be defined as follows

$$
v^{(-)}(x, z) \equiv E\left(\bar{\pi}\left(e_{i}, e_{-i}, z\right) \mid e_{i}=x, e_{k}<z \leq e_{l}\right) .
$$

The following proposition derives an equilibrium bidding function and necessary and sufficient conditions for a symmetric decreasing bidding equilibrium to exist. 
Proposition 3. If $v_{x}^{(-)}<0$ and $v_{x}^{(-)}(e, e)+v_{z}^{(-)}(e, e)<0$ for all $e \in[\underline{e}, \bar{e}]$, then there exists a unique symmetric decreasing bidding equilibrium given by $b^{(-)}(e)=v^{(-)}(e, e)$. If the equilibrium exists, then $v_{x}^{(-)}(e, e) \leq 0$ and $v_{x}^{(-)}(e, e)+v_{z}^{(-)}(e, e) \leq 0$ for all $e \in[e, \bar{e}]$.

The proof of Proposition 3 is similar to the proof of Proposition 1 and is, therefore, omitted. Consider first the condition $v_{x}^{(-)}<0$. If firms types are independent, then

$$
v_{x}^{(-)}(x, z) \equiv E\left(\overline{\pi_{i}}\left(x, e_{-i}, z\right) \mid e_{k}<z \leq e_{l}\right) .
$$

Under the assumption that firms prefer being more cost-efficient themselves we have that $\bar{\pi}_{i}\left(x, e_{-i}, z\right)>0$ and, therefore, $v_{x}^{(-)}>0$. Hence, a decreasing equilibrium never exists if types are statistically independent.

If, on the other hand, there is no strategic effect, i.e., $\overline{\pi_{j}}=\overline{\pi_{z}}=0$, and firms have local monopolies, we have $v_{x}^{(-)}(x, z)=\overline{\pi_{i}}=\pi_{e}>0$. Hence, also in this case a decreasing equilibrium does not exist.

In the remaining of this section, we provide an example of market conditions where a unique symmetric bidding equilibrium exists that is decreasing. To this end, we take the following distribution $F^{*}$ of firms' efficiency parameters $e_{j}$. Let a macroeconomic fundamental (e.g., interest rate, oil price, the growth rate of the economy etc.) $\beta$ be distributed over the interval $[0,1]$ in accordance with an arbitrary (twice differentiable) distribution function $F_{\beta}(t) \equiv \operatorname{Pr}(\beta<t)$. Then, for any given $\beta$ let all $e_{j}$ be independently and uniformly distributed over the interval $[\underline{x}(\beta), \bar{x}(\beta)]$, where $\underline{x}(\beta) \equiv \beta-\varepsilon \beta(1-\beta)$, $\bar{x}(\beta) \equiv \beta+\varepsilon \beta(1-\beta)$, and $\varepsilon \in(0,1)$ is a parameter, i.e., let the conditional distribution $F_{e}(x \mid t) \equiv \operatorname{Pr}\left(e_{j}<x \mid \beta=t\right)$ be
$\quad F_{e}(x \mid t)=\frac{x-\underline{x}(t)}{\bar{x}(t)-\underline{x}(t)}$ for $x \in[\underline{x}(t), \bar{x}(t)]$.

The reason why we consider this specific distribution is that for small values of $\varepsilon$, if a firm $i$ has a type $x$, the distribution of types of all other firms conditional on $x$ is concentrated on a small neighborhood of $x$. Therefore, all firms that are competing in the aftermarket have approximately the same type, the Nash equilibrium is almost symmetric, and a decreasing equilibrium bidding function can be analytically calculated 


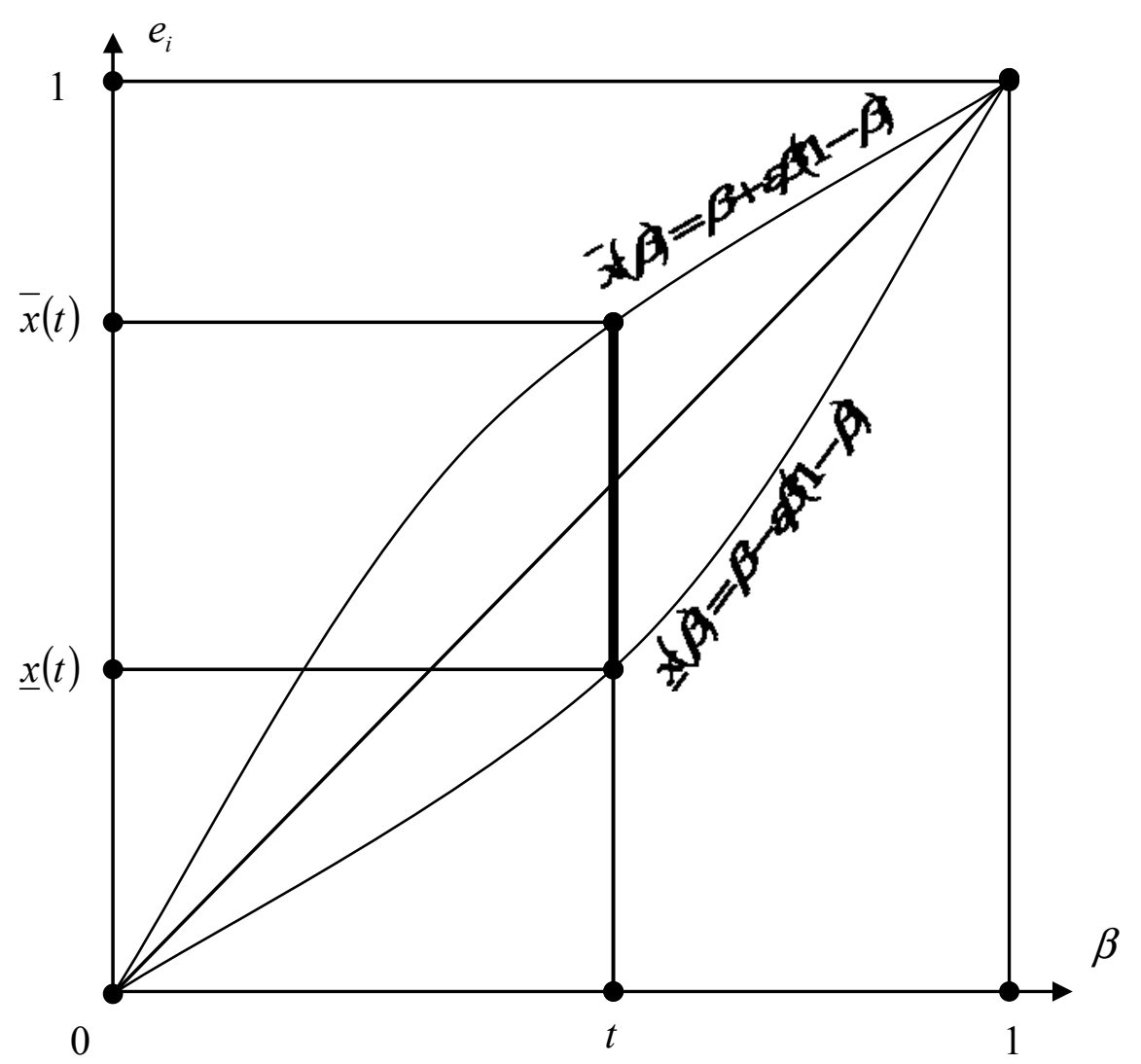

Figure 1. Support of the conditional distribution $F_{e}(x \mid t)=\operatorname{Pr}\left(e_{j}<x \mid \beta=t\right)$.

in the limit when $\varepsilon$ converges to zero. Figure 1 shows the support $[\underline{x}(t), \bar{x}(t)]$ of the conditional distribution $F_{e}(x \mid t)$.

Proposition 4. Let $N=n+1$ firms with constant marginal costs $c-e_{i}>0$ compete in an auction for $n$ licenses, let the winning firms compete in quantities in a market with constantly elastic demand $Q=p^{-r}$, and let firms' efficiency parameters $e_{i}$ be distributed in accordance with the distribution $F^{*}$. If the price elasticity $r$ satisfies

$$
\frac{1}{n}<r<\bar{r}(n) \equiv \frac{n^{2}+n+2}{3 n^{2}+3 n-2},
$$

then there exists an $\widetilde{\mathcal{E}}(r, n)>0$ so that for all $\varepsilon \in(0, \widetilde{\mathcal{E}})$ the auction stage has a unique symmetric bidding equilibrium that is decreasing.

In the example considered in Proposition 4, the demand elasticity $r$ must not be too small $(r>1 / n)$ in order to ensure that the aftermarket Nash equilibrium exists and is stable. On the other hand, $r$ must be small enough $(r<\bar{r}(n))$ so that the strategic effect 
is sufficiently strong. The minimum number of licenses for this decreasing equilibrium to exists is $n=3$. The main reason is that the strategic effect should be strong enough and this effect gets stronger, the larger the number of firms competing in the market place. $^{8}$

\section{Discussion and Conclusion}

In this article, we have shown that when multiple licenses are auctioned to firms which compete in an aftermarket, these licenses do not have to end up in the hands of the most efficient firms. This implies that auctions may create aftermarket inefficiencies. The main reasons for this result are the presence of an informational externality and the fact that rational bidders take a kind of adverse selection or winner's curse into account. Jehiel and Moldovanu (2006) argue that in case firms' aftermarket profits depend on private information in the hands of other winning firms (in our case cost) there is an informational externality. The kind of adverse selection or winner's curse that is present in our context is that firms prefer to compete with less efficient firms and that when the auction selects the most efficient firms, bidding firms have to take this selection effect into account. We have identified conditions under which efficient firms downsize their bid so much more than less efficient firms that an increasing bidding equilibrium does not exist.

The model developed in this paper does not fit into the now standard assumptions of the affiliated valuation model (Milgrom and Weber, 1982). An important assumption in the affiliated valuation model is that a player's valuation is an increasing function of his own signal as well as of the private signals received by all other players. In our case, where firms receive a signal of their cost parameter, firms' valuation is an increasing function of its own signal, but a decreasing function of the signals of other firms. Moreover, but less important, a firm only cares about the signals received by other winning firms.

In this paper, we have focused our attention only on a standard multi-unit uniformprice auction. It can be shown, however, that other simultaneous-bid multi-unit

\footnotetext{
${ }^{8}$ Formally, the proposition is stated for the case where the number of interested firms is just one more than the number of available licenses. This is a technical requirement as otherwise we cannot integrate out the expressions in the profit function.
} 
auctions, e.g., a pay-your-bid auction, also suffer from aftermarket inefficiency provided the strategic effect or the ex-ante types' correlation is sufficiently strong. Firms' desire to compete with less efficient competitors is responsible for such inefficiency. The analysis is much more complicated in case of sequential auctions, where licenses are sold one-by-one. It is easy to see that the last license ends up in hands of the most efficient remaining firm. Nevertheless, the strategic effect might create inefficient allocations in selling preceding licenses.

We have not allowed for resale in this paper. Resale opens up the possibility that in case of an inefficient allocation of licenses, an efficient firm buys a license from a less efficient firm. Such a single transaction would also be mutually beneficial because for given competitors' efficiency levels, an efficient firm makes more profits than a less efficient firm does. However, it is much less clear whether such a transaction is feasible in case other firms are also allowed to transact so that a sequential resale market would emerge. Analyzing the model while allowing for reselling turns out to be quite complicated. Apart from the fact that reselling is sometimes not allowed or prohibitively costly, there is another good reason not to consider the possibility of reselling. For example, in case a decreasing equilibrium exists, $n$ most efficient firms together make less profit than $n$ least efficient firms do. If, together with reselling, we allow firms to make side payments to other firms for not selling their licenses, one can show that the license holders (together) can "outbid" an offer of a more efficient firm as the profits they would loose when this new firm competes in the market are larger than the profit the newcomer could make. Hence, a decreasing bidding equilibrium yields an ex-post efficient allocation from the perspective of the coalition of winning firms.

This paper does not consider the question whether an optimal mechanism exist in the present situation. This is an interesting, but non-trivial, question. What is clear, however, is that the results obtained by Ausubel (2004) do not directly apply, as the present model does not satisfy the standard assumptions of the affiliated valuation model (as indicated above). 


\section{References}

Ausubel, L. 2004. An Efficient Ascending Bid Auction for Multiple Objects. American Economic Review 94 (5), p. 1452-75.

Binmore, K. and P. Klemperer. 2002. The Biggest Auction Ever: The Sale of the British 3G Telecom Licenses. Economic Journal 112, C-74-96.

Bulow, J., J. Geanokoplos, and P. Klemperer. 1985. Multi-market Oligopoly: strategic substitutes and complements. Journal of Political Economy 93, p. 488-511.

Demsetz, H. 1968. Why Regulate Utilities? Journal of Law and Economics, 11, p. 55-66.

Goeree, J. 2003. Bidding for the Future. Journal of Economic Theory 108 (2), p. 345-364.

Hoppe, H., Ph. Jehiel and B. Moldovanu. 2006. License Auctions and Market Structure, Journal of Economics and Management Strategy (forthcoming)

Janssen, M.C.W. 2001. De Draad Kwijt? (An Independent Evaluation of the Dutch UMTS auction commissioned by the Dutch Parliament).

Janssen, M.C.W. 2006. Auctions as Coordination Devices. European Economic Review 50, p. 517-532.

Janssen, M.C.W. and V. Karamychev 2006. Selection Effects in Auctions for Monopoly Rights. Journal of Economic Theory (forthcoming).

Jehiel, P. and B. Moldovanu. 1996. Strategic Non-Participation. RAND Journal of Economics 27(1), pp. 84-98.

Jehiel, P. and B. Moldovanu. 2001. Auctions with Downstream Interaction among Buyers. Rand Journal of Economics 31, 768-791.

Jehiel, P. and B. Moldovanu. 2003. An Economic Perspective on Auctions. Economic Policy 36, 271-308

Jehiel, P. and B. Moldovanu. 2006. Allocative and Informational Externalities in Auctions and Related Mechanisms, in R. Blundell, W. Newey, and T. Persson (eds.), The Proceedings of the 9th World Congress of the Econometric Society, Cambridge University Press.

Jehiel, P., B. Moldovanu and E. Stacchetti. 1996. How (not) to Sell Nuclear Weapons, American Economic Review 86(4), pp. 814-829. 
Klemperer, P. 2002a. What really matters in auction design? Journal of Economic Perspectives 16, p. 169-189.

Klemperer, P. 2002b. How not to run auctions: the European $3 \mathrm{G}$ mobile telecom auctions. European Economic Review 46, p. 829-845.

Laffont, J.J. and J. Tirole. 2002. A Theory of Incentives in Procurement and Regulation. MIT Press.

Milgrom, P. and R. Weber. 1982. A Theory of Auctions and Competitive Bidding. Econometrica 50, p. 1089-22. 


\section{Appendix}

Proof of Proposition 1. Let us define $Z$ to be the type of the firm that submits the $n^{\text {th }}$ highest bid amongst all $(N-1)$ firms other than firm i, i.e., $Z$ is the $n^{\text {th }}$ highest order statistics among $e_{j}, j \neq i$. We denote the distribution of $Z$ conditional on $e_{i}=x$ by $G^{(+)}(z \mid x)=\operatorname{Pr}\left(Z<z \mid e_{i}=x\right)$, and the corresponding density function by $g^{(+)}(z \mid x)$.

Suppose that all firms other than $i$ follow the bidding function $b^{(+)}(e)$, and $Z$ takes a value $z$. We consider a firm $i$, which has a cost parameter $e_{i}=x$ and which bids $b^{(+)}(y)$. If $y<z$, firm $i$ looses the auction and receives no profit. If, on the other hand, $y>z$, firm $i$ gets a license at the auction price $w=b^{(+)}(z)$, which yields the conditional expected profit $v^{(+)}(x, z)-b^{(+)}(z)$ to firm $i$. The unconditional expected profit of a firm with cost parameter $x$ and a bid $b^{(+)}(y)$ is

$$
V^{(+)}(x, y)=\int_{z<y}\left(v^{(+)}(x, z)-b^{(+)}(z)\right) g^{(+)}(z \mid x) d z .
$$

Maximizing $V^{(+)}(x, y)$ with respect to $y$ yields the first-order condition $x=\arg \max _{y}(x, y)$, i.e., $b^{(+)}(x)=v^{(+)}(x, x)$. The necessary second-order condition in this case can be written as $v_{x}^{(+)}(x, x) \geq 0$. Finally, $b^{(+)}(x)=v^{(+)}(x, x)$ is an increasing function only if $v_{x}^{(+)}(x, x)+v_{z}^{(+)}(x, x) \geq 0$.

Suppose now that $v_{x}^{(+)}>0$ and $v_{x}^{(+)}(x, x)+v_{z}^{(+)}(x, x)>0$. In order to check that $b^{(+)}(x)=v^{(+)}(x, x)$ is indeed an optimal bid, we evaluate $V^{(+)}(x, x)-V^{(+)}(x, y)$ for any $y \neq x:$

$$
\begin{aligned}
V^{(+)}(x, x)-V^{(+)}(x, y) & =\int_{y<z<x}\left(v^{(+)}(x, z)-v^{(+)}(z, z)\right) g^{(+)}(z \mid x) d z \\
& =\int_{y}^{x}\left(\int_{z}^{x} v_{x}^{(+)}(t, z) d t\right) g^{(+)}(z \mid x) d z \geq 0
\end{aligned}
$$

This shows that firm $i$ has no profitable deviations.

Proof of Lemma 1. If a firm $i$ gets a license, has a type $e_{i}=x$, and chooses $s_{i}$, whereas all its competitors have the same type $z$, the market profit of firm $i$ can be written as follows:

$$
E\left(\pi\left(s_{i}, s_{-i}, e_{i}\right) \mid e_{i}=x, e_{k}=z\right) .
$$


Maximizing this expression with respect to $s_{i}$ yields the following first-order condition:

$$
\left.0=E\left(\pi_{i}\left(s_{i}^{*}, s_{-i}^{*}, e_{i}\right)\right) e_{i}=x, e_{k}=z\right)=\pi_{i}\left(s(x, z), s_{-i}^{*}, x\right) .
$$

Differentiating it with respect to $x$ and $z$, taking into account that firm $i$ is of type $x$ and all other firms are of type $z$ and choose $s_{k}^{*}=s(z, z)$, and evaluating the resulting expression at $z=x$ yields:

$$
\begin{aligned}
& 0=\pi_{i, i} \frac{\partial s}{\partial e}+\pi_{i, e} \text { and } \\
& 0=\pi_{i, i} \frac{\partial s}{\partial z}+(n-1) \pi_{i, j}\left(\frac{\partial s}{\partial e}+\frac{\partial s}{\partial z}\right) .
\end{aligned}
$$

Solving them together provides us with the following partials of the Nash equilibrium strategy $s(x, z)$ at $z=x$ :

$$
\begin{aligned}
& \frac{\partial s}{\partial e}=-\frac{\pi_{i, e}}{\pi_{i, i}} \text { and } \\
& \frac{\partial s}{\partial z}=\frac{(n-1) \pi_{i, j} \pi_{i, e}}{\left(\pi_{i, i}+(n-1) \pi_{i, j}\right) \pi_{i, i}} .
\end{aligned}
$$

Then, substituting these expressions into $\overline{\pi_{j}}=(\partial s / \partial e) \pi_{j}$ and $\overline{\pi_{z}}=(n-1)(\partial s / \partial z) \pi_{j}$ finally yields

$$
\begin{aligned}
& \bar{\pi}_{i}(x, x, x)=\pi_{e}>0, \\
& \bar{\pi}_{j}(x, x, x)=-\frac{\pi_{j} \pi_{i, e}}{\pi_{i, i}}<0 \text { and } \\
& \bar{\pi}_{z}(x, x, x)=\frac{(n-1)^{2} \pi_{j} \pi_{i, j} \pi_{i, e}}{\left(\pi_{i, i}+(n-1) \pi_{i, j}\right) \pi_{i, i}} .
\end{aligned}
$$

In quantity competition settings it is $\pi_{j}<0$ and $\pi_{i, e}>0$ whereas in price competition for substitutes it is $\pi_{j}>0$ and $\pi_{i, e}<0$. Therefore, $\overline{\pi_{z}}(x, x, x)>0$ when $s$ are strategic substitutes $\left(\pi_{i, j}>0\right)$, and $\overline{\pi_{z}}(x, x, x)<0$ when $s$ are strategic complements $\left(\pi_{i, j}<0\right)$. 
Proof of Proposition 2. We will show that under the condition of the proposition, the necessary existence condition $v_{x}^{(+)}(e, e)+v_{z}^{(+)}(e, e) \geq 0$ for an increasing equilibrium fails at $e=\bar{e}$. To this end, we first calculate firms' aftermarket Nash equilibrium strategy $s(\bar{e}, \bar{e})$ and its partial derivatives. Then, we calculate firms' valuation function $v^{(+)}(\bar{e}, \bar{e})$ and its partial derivatives.

In the limit when $(x, z) \rightarrow(\bar{e}, \bar{e})$, the Nash equilibrium strategy $s(x, z)$ can be written as $s(x, z)=s^{(0)}-(\bar{e}-x) s^{(1)}-(\bar{e}-z) s^{(2)}$, where

$$
\begin{aligned}
s^{(0)} & \equiv s(\bar{e}, \bar{e}), \\
s^{(1)} & \equiv \frac{\partial s}{\partial x}(\bar{e}, \bar{e}), \text { and } \\
s^{(2)} & \equiv \frac{\partial s}{\partial z}(\bar{e}, \bar{e}) .
\end{aligned}
$$

Dropping arguments in all functions evaluated at $(x, z)=(\bar{e}, \bar{e})$, the first-order condition $0=E\left(\pi_{i}\left(s_{i}^{*}, s_{-i}^{*}, e_{i}\right) e_{i}=x, e_{l} \leq z<e_{k}\right)$ for independent types in the first-order approximation becomes

$$
\begin{aligned}
0 & =E\left(\pi_{i}-\left((\bar{e}-x) s^{(1)}+(\bar{e}-z) s^{(2)}\right) \pi_{i, i}-(n-1)\left(\left(\bar{e}-e_{k}\right) s^{(1)}+(\bar{e}-z) s^{(2)}\right) \pi_{i, j}-(\bar{e}-x) \pi_{i, e} \mid z<e_{k}\right) \\
& =\pi_{i}-\left(\pi_{i, i} s^{(1)}+\pi_{i, e}\right)(\bar{e}-x)-\left(\pi_{i, i} s^{(2)}+(n-1) \pi_{i, j}\left(s^{(2)}+\lim _{z \uparrow \bar{e}} \frac{E\left(\bar{e}-e_{k} \mid z<e_{k}\right)}{\bar{e}-z} s^{(1)}\right)\right)(\bar{e}-z)
\end{aligned}
$$

At $(x, z)=(\bar{e}, \bar{e})$, the first-order condition implies $0=\pi_{i}$. Then, denoting

$$
\widetilde{E} \equiv \lim _{z \uparrow \bar{e}} \frac{E\left(\bar{e}-e_{k} \mid z<e_{k}\right)}{\bar{e}-z},
$$

the first-order condition implies the following two equations determining $s^{(1)}$ and $s^{(2)}$ :

$$
\left\{\begin{array}{l}
0=\pi_{i, i} s^{(1)}+\pi_{i, e} \\
0=\pi_{i, i} s^{(2)}+(n-1) \pi_{i, j}\left(s^{(2)}+\widetilde{E} s^{(1)}\right)
\end{array} .\right.
$$

Solving this system yields

$$
\left\{\begin{array}{l}
s^{(1)}=-\frac{\pi_{i, e}}{\pi_{i, i}} \\
s^{(2)}=\frac{(n-1) \pi_{i, j} \pi_{i, e}}{\pi_{i, i}\left(\pi_{i, i}+(n-1) \pi_{i, j}\right)} \widetilde{E}
\end{array}\right.
$$

Hence, firms' valuation function $v^{(+)}(x, z)$ in the limit $(x, z)=(\bar{e}, \bar{e})$ can be written as 


$$
\begin{aligned}
v^{(+)}(x, z) & =E\left(\pi-(n-1)\left(\left(\bar{e}-e_{k}\right) s^{(1)}+(\bar{e}-z) s^{(2)}\right) \pi_{j}-(\bar{e}-x) \pi_{e} \mid z<e_{k}\right) \\
& =\pi-(n-1)\left(\widetilde{E} s^{(1)}+s^{(2)}\right) \pi_{j}(\bar{e}-z)-(\bar{e}-x) \pi_{e} \\
& =\pi+\frac{(n-1) \pi_{j} \pi_{i, e} \widetilde{E}}{\left(\pi_{i, i}+(n-1) \pi_{i, j}\right)}(\bar{e}-z)-(\bar{e}-x) \pi_{e}
\end{aligned}
$$

Finally, the necessary condition $v_{x}^{(+)}(e, e)+v_{z}^{(+)}(e, e) \geq 0$ for an increasing equilibrium to exist fails at $e=\bar{e}$ if

$$
0>v_{x}^{(+)}(\bar{e}, \bar{e})+v_{z}^{(+)}(\bar{e}, \bar{e})=\pi_{e}-\frac{(n-1) \pi_{j} \pi_{i, e} \widetilde{E}}{\left(\pi_{i, i}+(n-1) \pi_{i, j}\right)} .
$$

In accordance with Lemma $1, \pi_{j} \pi_{i, e}<0$. Hence, the above inequality can be written as

$$
\widetilde{E}>\frac{\pi_{e}\left(\pi_{i, i}+(n-1) \pi_{i, j}\right)}{(n-1) \pi_{j} \pi_{i, e}} .
$$

Calculating $\widetilde{E}$ yields:

$$
\widetilde{E}=\lim _{z \uparrow_{e}} \frac{E\left(\bar{e}-e_{k} \mid z<e_{k}\right)}{\bar{e}-z}=\lim _{z \uparrow^{\uparrow} \bar{e}} \frac{\int_{z}^{\bar{e}}(\bar{e}-x) f_{e}(x) d x}{(\bar{e}-z) \int_{z}^{e} f_{e}(x) d x}=1-\lim _{z \uparrow_{e}} \frac{f_{e}(z)}{2 f_{e}(z)-(\bar{e}-z) f_{e}{ }^{\prime}(z)} \geq \frac{1}{2} .
$$

The last inequality holds as an equality if $f_{e}(z \uparrow \bar{e})>0$, and as a strict inequality if $f_{e}(z \uparrow \bar{e})=0$ (so that $f_{e}{ }^{\prime}(z \uparrow \bar{e}) \leq 0$ ). Therefore, the necessary existence condition fails if

$$
2 \pi_{e}<\frac{(n-1) \pi_{j} \pi_{i, e}}{\left(\pi_{i, i}+(n-1) \pi_{i, j}\right)} .
$$

This ends the proof.

Proof of Proposition 4. First, we derive firms' aftermarket Nash equilibrium strategy, which we denote by $s(x, z ; \varepsilon)$ to emphasize its dependence on $\varepsilon$, under the assumption that in the auction stage all they follow an increasing bidding function $b^{(+)}(e)$. Under the assumption that the profit function $\pi$ is twice continuously differentiable, $s(x, z ; \varepsilon)$ is continuously differentiable with respect to all its argument, and we represent it as a first-order Tailor expansion. We show that this bidding function $b^{(+)}(e)$ does not satisfy the second order condition, hence, an increasing symmetric bidding equilibrium does not exist. Second, we repeat the previous exercise for a decreasing bidding function 
$b^{(-)}(e)$ and analyze conditions under which $b^{(-)}(e)$ is indeed an equilibrium bidding function.

From now on we denote by $x$ a type of a firm $i$. Types of all other (winning and loosing) firms are $e_{j},\left(e_{k}\right.$ and $e_{l}=z$ respectively $)$, and we define

$$
\begin{aligned}
& \lambda_{j} \equiv\left(e_{j}-x\right) / \varepsilon, \\
& \underline{t}(x) \equiv\left((1+\varepsilon)-\sqrt{(1+\varepsilon)^{2}-4 \varepsilon x}\right) /(2 \varepsilon) \text { and } \\
& \bar{t}(x) \equiv\left(\sqrt{(1-\varepsilon)^{2}+4 \varepsilon x}-(1-\varepsilon)\right) /(2 \varepsilon),
\end{aligned}
$$

so that for any $x \in[0,1]$ :

$$
x \equiv \underline{x}(\bar{t}(x)) \text { and } x \equiv \bar{x}(\underline{t}(x)) .
$$

Thus, for given $x$, conditional distribution $F_{\beta}(t \mid x) \equiv \operatorname{Pr}\left(\beta<t \mid e_{i}=x\right)$ has the support $[\underline{t}(x), \bar{t}(x)]$, and conditional distribution $F_{e}(\lambda \mid x) \equiv \operatorname{Pr}\left(\lambda_{j}<\lambda \mid e_{i}=x\right)$ has the support $[\underline{\lambda}(x), \bar{\lambda}(x)]$, where both $\underline{\lambda}(x)$ and $\bar{\lambda}(x)$ are bounded: ${ }^{9}$

$$
\begin{aligned}
& \underline{\lambda}(x)=(\underline{t}-x) / \varepsilon-\underline{t}(1-\underline{t}) \geq-0.5 \text { and } \\
& \bar{\lambda}(x)=(\bar{t}-x) / \varepsilon+\bar{t}(1-\bar{t}) \leq 0.5 .
\end{aligned}
$$

Denoting $s(x, z ; \varepsilon)$ itself and its partial derivatives evaluated at $(x, x ; 0)$ as

$$
\begin{aligned}
& s^{(0)}(x) \equiv s(x, x ; 0), \\
& s^{(1)}(x) \equiv \frac{\partial s}{\partial x}(x, x ; 0), \\
& s^{(2)}(x) \equiv \frac{\partial s}{\partial z}(x, x ; 0), \text { and } \\
& s^{(3)}(x) \equiv \frac{\partial s}{\partial \varepsilon}(x, x ; 0),
\end{aligned}
$$

allows $s(x, z ; \varepsilon)$ and $s\left(e_{j}, z ; \varepsilon\right)$ to be written in the first-order approximation as

$$
\begin{aligned}
& s(x, z ; \varepsilon)=s^{(0)}+\left(s^{(2)} \lambda_{z}+s^{(3)}\right) \varepsilon \text { and } \\
& s\left(e_{j}, z ; \varepsilon\right)=s^{(0)}+\left(\lambda_{j} s^{(1)}+\lambda_{z} s^{(2)}+s^{(3)}\right) \varepsilon .
\end{aligned}
$$

Dropping arguments lists in all functions evaluated at $z=x$, we write the first-order condition

\footnotetext{
${ }^{9}$ These inequalities can be obtained by minimizing $\underline{\lambda}(x)$ and maximizing $\bar{\lambda}(x)$ with respect to $x$.
} 


$$
0=E\left(\pi_{i}\left(s(x, z ; \varepsilon), s\left(e_{1}, z ; \varepsilon\right), \ldots, e_{i}\right) \mid e_{i}=x, e_{l}=z<e_{k}\right)
$$

as follows:

$$
\begin{aligned}
0 & \left.=E\left(\pi_{i}\left(s^{(0)}+\left(s^{(2)} \lambda_{z}+s^{(3)}\right) \mathcal{E}, s^{(0)}+\left(\lambda_{1} s^{(1)}+\lambda_{z} s^{(2)}+s^{(3)}\right) \varepsilon, \ldots, x\right)\right) e_{i}=x, e_{l}=z<e_{k}\right) \\
& =E\left(\pi_{i}+\varepsilon\left(\pi_{i, i}\left(s^{(2)} \lambda_{z}+s^{(3)}\right)+\pi_{i, j}\left(s^{(1)} \sum_{k} \lambda_{k}+(n-1)\left(s^{(2)} \lambda_{z}+s^{(3)}\right)\right)\right) \mid e_{i}=x, e_{l}=z<e_{k}\right) \\
& =\pi_{i}+\left(\left(\pi_{i, i}+(n-1) \pi_{i, j}\right)\left(s^{(2)} \lambda_{z}+s^{(3)}\right)+(n-1) \pi_{i, j} s^{(1)} \lim _{\varepsilon \rightarrow 0} E\left(\lambda_{k} \mid e_{i}=x, e_{l}=z<e_{k}\right)\right) \varepsilon
\end{aligned}
$$

Let, first, $\varepsilon=0$. In this case, the first-order condition implies $0=\pi_{i}$, which for a given profit function

$$
\left.\pi\left(s_{i}, s_{-i}, e_{i}\right)=s_{i}\left(\sum_{j} s_{j}\right)^{-1 / r}-c+e_{i}\right)
$$

yields the symmetric aftermarket Nash equilibrium strategy (see section 3):

$$
s(x, x ; 0)=s^{(0)}=\frac{1}{n}\left(\frac{(n r-1)}{n r(c-x)}\right)^{r} .
$$

In this case

$$
\begin{aligned}
& \pi=\frac{(c-x) s^{(0)}}{(n r-1)}, \\
& \pi_{j}=-\frac{(c-x)}{(n r-1)}, \\
& \pi_{i, i}=-\frac{(2 n r-(1+r))(c-x)}{(n r-1) n r s^{(0)}}, \\
& \pi_{i, j}=-\frac{(n r-(1+r))(c-x)}{(n r-1) n r s^{(0)}}, \text { and } \\
& s^{(1)}+s^{(2)}=\frac{r s^{(0)}}{(c-x)} .
\end{aligned}
$$

Using $0=\pi_{i}$, we rewrite the first-order condition for $\varepsilon \neq 0$ and $\lambda_{z}=0$ as follows:

$$
0=\left(\pi_{i, i}+(n-1) \pi_{i, j}\right) s^{(3)}+(n-1) \pi_{i, j} s^{(1)} \lim _{\varepsilon \rightarrow 0} \frac{E\left(e_{k} \mid e_{i}=x, e_{l}=z<e_{k}\right)-x}{\varepsilon},
$$

so that

$$
s^{(3)}=-\frac{(n-1) \pi_{i, j}}{\left(\pi_{i, i}+(n-1) \pi_{i, j}\right)} s^{(1)} \lim _{\varepsilon \rightarrow 0} \frac{H^{(+)}(x, x)-x}{\varepsilon},
$$

where we defined functions

$$
H^{( \pm)}(x, z) \equiv E\left(e_{k} \mid e_{i}=x, e_{l}=z, \pm z< \pm e_{k}\right) .
$$


Properties of $H^{( \pm)}(x, z)$ are derived in the following lemma, which is proven after the proof of the proposition.

Lemma 2. Let $e_{i}$ be distributed in accordance with the distribution function $F^{*}$. Then, $H^{( \pm)}(x, z)$ for small $\varepsilon$ can be written as follows:

$$
H^{( \pm)}(x, z)=\frac{n x+(n+2) z}{2(n+1)} \pm \frac{n x(1-x)}{(n+1)} \varepsilon+o(\varepsilon),
$$

Using Lemma 2, we rewrite $s^{(3)}$ as follows:

$$
s^{(3)}=-\frac{n(n-1) \pi_{i, j} x(1-x)}{(n+1)\left(\pi_{i, i}+(n-1) \pi_{i, j}\right)} s^{(1)}
$$

Plugging this expression into the first-order condition yields:

$$
\begin{aligned}
s^{(2)} & =-\frac{(n-1) \pi_{i, j}}{(n+1)\left(\pi_{i, i}+(n-1) \pi_{i, j}\right)} s^{(1)} \lim _{\varepsilon \rightarrow 0} \frac{(n+1)\left(E\left(e_{k} \mid e_{i}=x, e_{l}=z<e_{k}\right)-x\right)-n x(1-x) \varepsilon}{(z-x)} \\
& =-\frac{(n+2)(n-1) \pi_{i, j}}{2(n+1)\left(\pi_{i, i}+(n-1) \pi_{i, j}\right)} s^{(1)}
\end{aligned}
$$

Solving $s^{(1)}+s^{(2)}=r s^{(0)} /(c-x)$ together with the above expressions for $s^{(2)}$ and $s^{(3)}$ finally yields:

$$
\begin{aligned}
& s^{(1)}=\frac{2 r(n+1)\left(\pi_{i, i}+(n-1) \pi_{i, j}\right)}{(c-x)\left(2(n+1) \pi_{i, i}+n(n-1) \pi_{i, j}\right)} s^{(0)}, \\
& s^{(2)}=-\frac{r(n+2)(n-1) \pi_{i, j}}{(c-x)\left(2(n+1) \pi_{i, i}+n(n-1) \pi_{i, j}\right)} s^{(0)}, \text { and } \\
& s^{(3)}=-\frac{2 r n(n-1) \pi_{i, j} x(1-x)}{(c-x)\left(2(n+1) \pi_{i, i}+n(n-1) \pi_{i, j}\right)} s^{(0)} .
\end{aligned}
$$

Hence, the aftermarket Nash equilibrium strategy $s(x, z ; \varepsilon)$ for small $\varepsilon$ and $(z-x)$ is

$$
s(x, z ; \varepsilon)=\left(1-\frac{r(n-1) \pi_{i, j}((n+2)(z-x)+2 n x(1-x) \varepsilon)}{(c-x)\left(2(n+1) \pi_{i, i}+n(n-1) \pi_{i, j}\right)}\right) s^{(0)} .
$$

This ends the analysis of the aftermarket stage of the game.

In order show that an increasing symmetric bidding equilibrium does not exist for small $\varepsilon$, we calculate firms' valuation function $v^{(+)}(x, z ; \varepsilon)$, and verify that for given parameters' restrictions, $v_{x}^{(+)}(x, x ; 0)<0$. Using the first-order approximation for $s(x, z ; \varepsilon)$, firms' valuation function $v^{(+)}(x, z ; \varepsilon)$ in the first-order approximation can be written as follows: 


$$
\begin{aligned}
v^{(+)} & =E\left(\pi\left(s(x, z ; \varepsilon), s\left(e_{1}, z ; \varepsilon\right), z\right) \mid e_{i}=x, e_{l} \leq z<e_{k}\right) \\
& =E\left(\pi\left(s^{(0)}+\left(s^{(2)} \lambda_{z}+s^{(3)}\right) \varepsilon, s^{(0)}+\left(\lambda_{1} s^{(1)}+\lambda_{z} s^{(2)}+s^{(3)}\right) \varepsilon, \ldots, x\right) \mid e_{i}=x, e_{l}=z<e_{k}\right) \\
& =E\left(\pi+\pi_{j} \sum_{k}\left(\lambda_{k} s^{(1)}+\lambda_{z} s^{(2)}+s^{(3)}\right) \varepsilon \mid e_{i}=x, e_{l}=z<e_{k}\right) \\
& =\pi+(n-1) \pi_{j}\left(\left(\lim _{\varepsilon \rightarrow 0} \frac{\left(H^{(+)}(x, z)-x\right) s^{(1)}}{\varepsilon}+s^{(3)}\right) \mathcal{E}+s^{(2)}(z-x)\right) \\
& =\pi+\frac{r(n-1) \pi_{j} \pi_{i, i}((n+2)(z-x)+2 n x(1-x) \varepsilon)}{(c-x)\left(2(n+1) \pi_{i, i}+n(n-1) \pi_{i, j}\right)} s^{(0)}
\end{aligned}
$$

Substituting expressions for $\pi, \pi_{j}, \pi_{i, i}, \pi_{i, j}$, and $s^{(0)}$ finally yields the following valuation function $v^{(+)}(x, z ; \varepsilon)$ :

$$
v^{(+)}=\frac{1}{n^{2} r}\left(\frac{n r(c-x)}{(n r-1)}\right)^{1-r}\left(1-\frac{r(n-1)(2 n r-(1+r))((n+2)(z-x)+2 n x(1-x) \varepsilon)}{(c-x)(2(n+1)(2 n r-(1+r))+n(n-1)(n r-(1+r)))}\right)
$$

But then

$$
v_{x}^{(+)}(x, x ; 0)=-\left(\frac{n r(c-x)}{(n r-1)}\right)^{1-r} \frac{(n r-1)\left(\left(n^{2}+n+2\right)-\left(3 n^{2}+3 n-2\right) r\right)}{n^{2}(c-x)\left(\left(r\left(n^{2}+2 n+3\right)+1\right)(n r-1)+(1-r)(1+2 r)\right)}<0,
$$

provided $r<\bar{r}(n)$. This implies that $v_{x}^{(+)}(x, x ; \varepsilon)<0$ for sufficiently small (but strictly positive) $\varepsilon$, so that an increasing symmetric bidding equilibrium does not exist.

Suppose now that there exists a symmetric decreasing equilibrium bidding function $b^{(-)}(e)$. In a similar way as above, firms' valuation function $v^{(-)}(x, z ; \varepsilon)$ can be written as follows:

$$
v^{(-)}=\frac{1}{n^{2} r}\left(\frac{n r(c-x)}{(n r-1)}\right)^{1-r}\left(1-\frac{r(n-1)(2 n r-(1+r))((n+2)(z-x)-2 n x(1-x) \varepsilon)}{(c-x)(2(n+1)(2 n r-(1+r))+n(n-1)(n r-(1+r)))}\right) .
$$

But then

$$
v_{x}^{(-)}(x, x ; 0)=-\left(\frac{n r(c-x)}{(n r-1)}\right)^{1-r} \frac{(n r-1)\left(\left(n^{2}+n+2\right)-\left(3 n^{2}+3 n-2\right) r\right)}{n^{2}(c-x)\left(\left(r\left(n^{2}+2 n+3\right)+1\right)(n r-1)+(1-r)(1+2 r)\right)}<0,
$$

for $r<\bar{r}(n)$, and

$$
v_{z}^{(-)}(x, x ; 0)=-\left(\frac{n r(c-x)}{(n r-1)}\right)^{1-r} \frac{(n+2)(n-1)(2 n r-(1+r))}{n^{2}(c-x)(2(n+1)(2 n r-(1+r))+n(n-1)(n r-(1+r)))}<0 .
$$

By continuity argument, there exists an $\widetilde{\mathcal{E}}>0$ so that $v_{x}^{(-)}(x, z ; \varepsilon)<0$ and $v_{z}^{(-)}(x, z ; \varepsilon)<0$ for all $\varepsilon \in(0, \widetilde{\mathcal{E}})$ and feasible $z$. Therefore, the proposed function $b^{(-)}(x)=v^{(-)}(x, x)$ is indeed decreasing and is a unique symmetric equilibrium bidding function. 
Proof of Lemma 2. We denote distribution functions as follows:

$$
\begin{aligned}
& F_{\beta}(t) \equiv \operatorname{Pr}(\beta<t), \\
& F_{e}(x, z) \equiv \operatorname{Pr}\left(e_{i}<x, e_{k}>z\right), \text { and } \\
& F_{e}(x, z \mid t) \equiv \operatorname{Pr}\left(e_{i}<x, e_{k}>z \mid \beta=t\right),
\end{aligned}
$$

and the corresponding densities be

$$
\begin{aligned}
& f_{\beta}(t) \equiv d F_{\beta}(t) / d x=1, \\
& f_{e}(x, z) \equiv d F_{e}(x, z) / d x, \text { and } \\
& f_{e}(x, z \mid t) \equiv d F_{e}(x, z \mid t) / d x .
\end{aligned}
$$

As $e_{i} \sim U(\underline{x}(\beta), \bar{x}(\beta))$, it follows that for $x \in[\underline{x}(t), \bar{x}(t)]$ :

$$
F_{e}(x, z \mid t)= \begin{cases}\frac{(x-\underline{x}(t))(\bar{x}(t)-z)^{n-1}}{(\bar{x}(t)-\underline{x}(t))^{n}}, & \text { if } z \in(\underline{x}(t), \bar{x}(t)) \\ \frac{(x-\underline{x}(t))}{\bar{x}(t)-\underline{x}(t)}, & \text { if } z \in(0, \underline{x}(t))\end{cases}
$$

And, therefore,

$$
f_{e}(x, z \mid t)= \begin{cases}\frac{(\bar{x}(t)-z)^{n-1}}{(\bar{x}(t)-\underline{x}(t))^{n}}, & \text { if } z \in(t-\varepsilon t(1-t), \bar{x}(t)) \\ \overline{\bar{x}(t)-\underline{x}(t)}, & \text { if } z \in(0, t-\varepsilon t(1-t))\end{cases}
$$

Hence,

$$
\begin{aligned}
f_{\beta}(t \mid x, z) & \equiv \frac{f_{e}(x, z \mid t) f_{\beta}(t)}{f_{e}(x, z)} \\
& = \begin{cases}\frac{(\bar{x}(t)-z)^{n-1} f_{\beta}(t)}{(\bar{x}(t)-\underline{x}(t))^{n} f_{e}(x, z)}, & \text { if } t \in(\max (t(x), \underline{t}(z)), \min (\bar{t}(x), \bar{t}(z))) \\
\frac{f_{\beta}(t)}{(\bar{x}(t)-\underline{x}(t)) f_{e}(x, z)}, & \text { if } t \in(\min (\bar{t}(x), \bar{t}(z)), \bar{t}(x))\end{cases}
\end{aligned}
$$

where $\underline{t}$ and $\bar{t}$ are as defined in Proof of Proposition 4.

We define $\widetilde{H}^{(+)}(x, z, t) \equiv E\left(e_{k} \mid e_{i}=x, e_{l}=z<e_{k}, \beta=t\right)$ and consider two cases.

a) When $z \geq x, \widetilde{H}^{(+)}(x, z, t)=\frac{1}{2}(\bar{x}(t)+z)$ for $t \in(\underline{t}(z), \bar{t}(x))$. Hence, $H^{(+)}(x, z)$ can be written as

$$
H^{(+)}(x, z)=E_{\beta}\left(\widetilde{H}^{(+)}(x, z, \beta) \mid e_{i}=x, e_{l}=z<e_{k}\right)=P_{1}(x, z) / Q_{1}(x, z), \text { where }
$$




$$
P_{1}(x, z) \equiv f_{e}(x, z) \int_{t(z)}^{\bar{t}(x)} \frac{1}{2}(\bar{x}(t)+z) f_{\beta}(t \mid x, z) d t=\int_{t(z)}^{\bar{t}(x)} \frac{(\bar{x}(t)+z)(\bar{x}(t)-z)^{n-1} f_{\beta}(t)}{2(\bar{x}(t)-\underline{x}(t))^{n}} d t,
$$

and

$$
Q_{1}(x, z) \equiv f_{e}(x, z) \int_{t(z)}^{\bar{t}(x)} f_{\beta}(t \mid x, z) d t=\int_{\underline{t}(z)}^{\bar{i}(x)} \frac{(\bar{x}(t)-z)^{n-1} f_{\beta}(t)}{(\bar{x}(t)-\underline{x}(t))^{n}} d t .
$$

b) When $z \leq x, \quad \widetilde{H}^{(+)}(x, z, t)=\frac{1}{2}(\bar{x}(t)+z)$ for $t \in(t(x), \bar{t}(z))$ and $\widetilde{H}^{(+)}(x, z, t)=t$ for $t \in(\bar{t}(z), \bar{t}(x))$. Hence, $H^{(+)}(x, z)$ can be written as

$$
\begin{aligned}
& H^{(+)}(x, z)=E_{\beta}\left(\widetilde{H}^{(+)}(x, z, \beta) \mid e_{i}=x, e_{l}=z<e_{k}\right)=P_{2}(x, z) / Q_{2}(x, z), \text { where } \\
& P_{2}(x, z) \equiv \int_{\underline{t}(x)}^{\bar{t}(z)} \frac{(\bar{x}(t)+z)(\bar{x}(t)-z)^{n-1} f_{\beta}(t)}{2(\bar{x}(t)-\underline{x}(t))^{n}} d t+\int_{\bar{t}(z)}^{\bar{t}(x)} \frac{t f_{\beta}(t)}{\bar{x}(t)-\underline{x}(t)} d t,
\end{aligned}
$$

and

$$
Q_{2}(x, z)=\int_{t(x)}^{\bar{i}(z)} \frac{(\bar{x}(t)-z)^{n-1} f_{\beta}(t)}{(\bar{x}(t)-\underline{x}(t))^{n}} d t+\int_{\bar{t}(z)}^{\bar{i}(x)} \frac{f_{\beta}(t)}{\bar{x}(t)-\underline{x}(t)} d t .
$$

In order to evaluate $H^{(+)}(x, z)$ and its partials for small values of $\mathcal{E}$ we use the $3^{\text {rd }}$-order approximation $\sqrt{1+\varepsilon}=1+\frac{1}{2} \mathcal{E}-\frac{1}{8} \mathcal{E}^{2}+\frac{1}{16} \varepsilon^{3}+o\left(\varepsilon^{3}\right)$, so that

$$
\begin{aligned}
& \sqrt{(1-\varepsilon)^{2}+4 \varepsilon x}=1+(2 x-1) \mathcal{\varepsilon}+2 x(1-x) \mathcal{\varepsilon}^{2}+2 x(1-x)(1-2 x) \mathcal{E}^{3}+o\left(\varepsilon^{3}\right), \text { and } \\
& \sqrt{(1+\varepsilon)^{2}-4 \varepsilon x}=1-(2 x-1) \mathcal{\varepsilon}+2 x(1-x) \mathcal{\varepsilon}^{2}-2 x(1-x)(1-2 x) \mathcal{E}^{3}+o\left(\varepsilon^{3}\right) .
\end{aligned}
$$

Hence,

$$
\begin{aligned}
& \bar{t}(x)=x+x(1-x) \mathcal{E}+x(1-x)(1-2 x) \mathcal{E}^{2}+o\left(\varepsilon^{2}\right), \overline{t^{\prime}}(x)=1+o(1), \\
& \underline{t}(x)=x-x(1-x) \varepsilon+x(1-x)(1-2 x) \varepsilon^{2}+o\left(\varepsilon^{2}\right), \text { and } \underline{t}^{\prime}(x)=1+o(1),
\end{aligned}
$$

The uniform convergence with respect to $\varepsilon \in(0, \bar{\varepsilon}) \subset(0,1)$ of the limits

$$
\lim _{x \rightarrow 0} \frac{\bar{t}(x)}{x}=\lim _{x \rightarrow 1} \frac{1-\underline{t}(x)}{1-x}=\frac{1}{(1-\varepsilon)}, \text { and } \lim _{x \rightarrow 0} \frac{\underline{t}(x)}{x}=\lim _{x \rightarrow 1} \frac{1-\bar{t}(x)}{1-x}=\frac{1}{(1+\varepsilon)},
$$

implies the following expressions for $\underline{t}$ and $\bar{t}$ :

$$
\begin{aligned}
& \bar{t}(x)=x+x(1-x) \mathcal{E}(1+(1-2 x) \mathcal{E}+o(\varepsilon)), \text { and } \\
& \underline{t}(x)=x-x(1-x) \mathcal{\varepsilon}(1-(1-2 x) \mathcal{E}+o(\varepsilon)) .
\end{aligned}
$$

We consider cases $z \geq x$ and $z \leq x$ separately. 
a) Let $z \geq x$. Using the above Tailor expansions yields

$$
\begin{aligned}
& Q_{1}(x, z)=\frac{1}{n}\left(f_{\beta}(x)+\frac{n-1}{n+1}\left(f_{\beta}(x)(1-2 x)+f_{\beta}^{\prime}(x) x(1-x)\right) \varepsilon\right), \\
& \frac{\partial Q_{1}}{\partial x}(x, x)=\frac{\overline{t^{\prime}}(x)\left(f_{\beta}(x)+\left(f_{\beta}^{\prime}(x) x(1-x)-f_{\beta}(x)(1-2 x)\right) \varepsilon\right)}{2 x(1-x) \varepsilon}, \\
& \frac{\partial Q_{1}}{\partial z}(x, x)=-\frac{1}{2 x(1-x) \mathcal{\varepsilon}}\left(f_{\beta}(x)+\frac{n-2}{n} f_{\beta}^{\prime}(x) x(1-x) \varepsilon\right), \\
& P_{1}(x, x)=x Q_{1}(x, x)+\frac{f_{\beta}(x) x(1-x) \varepsilon}{n+1}, \\
& \frac{\partial P_{1}}{\partial x}(x, x)=\frac{-t^{\prime}(x)\left(f_{\beta}(x)+x\left(f_{\beta}(x)+f_{\beta}^{\prime}(x)(1-x)\right) \varepsilon\right)}{2(1-x) \varepsilon}, \text { and } \\
& \frac{\partial P_{1}}{\partial z}(x, x)=\frac{Q_{1}(x, x)}{2}-\frac{1}{2(1-x) \varepsilon}\left(f_{\beta}(x)+\frac{(1-x)}{n}\left((n-1) f_{\beta}(x)+(n-2) f_{\beta}^{\prime}(x) x\right) \varepsilon\right) .
\end{aligned}
$$

Hence,

$$
\begin{aligned}
& H^{(+)}(x, x+0)=x+\frac{n}{n+1} x(1-x) \mathcal{\varepsilon}, \\
& H_{x}^{(+)}(x, x+0)=\frac{n}{2(n+1)}, \text { and } \\
& H_{z}^{(+)}(x, x+0)=\frac{(n+2)}{2(n+1)} .
\end{aligned}
$$

b) Let $z \leq x$. As $P_{2}(x, x)=P_{1}(x, x)$ and $Q_{2}(x, x)=Q_{1}(x, x)$, it follows that $H^{(+)}(x, x-0)=H^{(+)}(x, x+0)$. Similarly, as $\partial P_{2} / \partial x=\partial P_{1} / \partial x, \partial P_{2} / \partial z=\partial P_{1} / \partial z$, $\partial Q_{2} / \partial x=\partial Q_{1} / \partial x$, and $\partial Q_{2} / \partial z=\partial Q_{1} / \partial z$ at $(x, x)$, it follows that $H_{x}^{(+)}(x, x-0)=H_{x}^{(+)}(x, x+0)$ and $H_{z}^{(+)}(x, x-0)=H_{z}^{(+)}(x, x+0)$.

Thus at $(x, x), H^{(+)}(x, z)$ is continuously differentiable with the partials $H_{x}^{(+)}(x, x)=n /(2(n+1))+o(1)$ and $H_{z}^{(+)}(x, x)=(n+2) /(2(n+1))+o(1)$ and, therefore, can be written as

$$
H^{(+)}(x, z)=\frac{n x+(n+2) z}{2(n+1)}+\frac{n x(1-x)}{(n+1)} \varepsilon+o(\varepsilon) .
$$

The expression for $H^{(-)}$immediately follows from $H^{(-)}(x, z)=1-H^{(+)}(1-x, 1-z)$. 